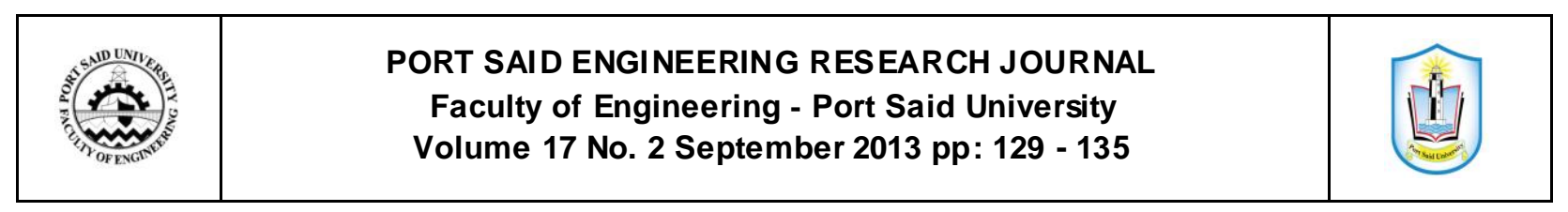

\title{
Effect of Rice Straw Ash on the Behaviour of High Performance Concrete Mixes
}

\author{
S. Nour Eldin ${ }^{1}$, K. Sharobim ${ }^{2,}$ H. Mokhtar ${ }^{3}$ and N. A. Hussein ${ }^{4}$
}

\begin{abstract}
This research aims to investigate the effect of rice straw ash on the behaviour of high performance concrete mixes. Using Rice Straw Ash will eliminate the environment pollution and provide a low cost construction material. RSA will be used as an additive or as a replacement of a part of cement content. The effects of RSA on the properties of fresh and hardened concrete were investigated to produce high performance concrete. The study includes measuring the workability of concrete by slump and slump flow tests. Also, it includes the properties of the hardened concrete such as compressive, tensile, and fle xural strength are measured.
\end{abstract}

\section{INTRODUCTION}

The Egyptian authorities have not yet controlled the pollution resulting from burning of rice chaff straw that, eventually, causes many serious diseases. In the fall of 1999, an autumnal black cloud appeared above several Egyptian cities, with a thick bitter-smelling fog, due to the rice straw burning [1]. The farmers burnt rice chaff to clear the fields for a new crop [2, 3]. According to the toxicology department of Cairo's Qasr El-Ayni University hospital, this could exacerbate respiratory and cardio-vascular illnesses, causing at least 5,000 additional deaths in the metropolis and its surroundings every year. In this work, authors suggest using the straw, instead of burning it. It shall be recycled with a mixture of cement to form a sustainable low cost building material, which also reduces atmospheric pollution. In addition to these benefits, the straw could act as a thermal insulation material for the unpleas ant Egyptian weather. The use of thermal insulation helps reduce energy costs, while creating pleasant indoor temperatures [1].

Rice-husk (RH) is an agricultural by-product material. It contains about 50\% cellulose, $25-30 \%$ lignin, and $15-20 \%$ of silica. When rice-husk is burnt rice-husk ash (RHA) is generated. On burning, cellulose and lignin are removed leaving behind silica ash [5]. The controlled te mperature and environment of burning yields better quality of rice husk ash, as its particle size and specific surface area are dependent on the burning conditions.

For every $1000 \mathrm{~kg}$ of milled paddy, about $200 \mathrm{~kg}$ $(20 \%)$ of husk is produced, and when this husk is burnt

\footnotetext{
${ }^{T}$ General Authority for Educational Buildings. Port Said, Egypt;

E-mail:salyhosny@gmail.com

${ }^{2}$ Department of Civil Engineering, Faculty of Engineering,

Suez Canal University, Ismailia, Egypt.

E-mail: k_sharobim@hotmail.com

${ }^{3}$ Department of Civil Engineering, Faculty of Engineering,

Suez Canal University, Ismailia, Egypt.

E-mail: elsaidy2000@hotmail.com

${ }^{4}$ Department of Civil Engineering, Faculty of Engineering, Port Said University, Port Said, Egypt.

E-mail: Nourallah@eng..psu.edu.eg
}

in the boilers, about $50 \mathrm{~kg}$ (5\%) of RHA is generated. Completely burnt rice-husk is grey to white in colour, while partially burnt rice-husk ash is blackish [5]. In fact, some previous researchers investigated the effect of adding rice husk ash to the concrete. Since, the rice husk ash (RHA) also consists of the same chemical compositions specially the pozzolanic materials which are reported to be $90-95 \%$ of the RHA when rice husk is exposed to the same burning conditions specified in the forgoing text. A tremendous similarity between the RHA and RSA has been found theoretically and experimental work becomes vital to investigate the RSA in concrete and the results eventually required [6]. High performance concrete (HPC) exceeds the properties and constructability of normal concrete. Normal and special materials are used to make these specially designed concretes meet some combination of performance requirements. Special mixing, placing, and curing practices are needed to produce and handle high-performance concrete. Also, extensive performance tests are usually required to demonstrate compliance with specific project needs. Highperformance concrete has been primarily used in tunnels, bridges, and tall buildings for its strength, durability, and high modulus of elasticity. It has also been used in poles, parking garages, and agricultural applications [7].Some research describes the effect of rice straw ash on the behaviour of high performance concrete. Rice straw can be burned and grinded to produce a pozzolanic construction material that can be used in making blended cement. The results indicated that the chemical and physical properties of grinded or calcined rice straw ash passed the ASTM requirement for pozzolanic material that can be used to blend with Portland cement [8].

\section{EXPERMINTAL PROGRAM}

\subsection{Material}

Based on the principal of high performance concrete, the materials used in the experiments are 
shown in Table (1). The cement used is Sinai Portland Cement $52.2 \mathrm{~N}$. The burned rice straw ash has a specific gravity of 2.2, and specific surface area of 10 $\mathrm{m}^{2} / \mathrm{g}$. The RSA has dark grey to whitish ash with particle density of $2200 \mathrm{Kg} / \mathrm{m} 3$ and fineness retained on 45 micro mills. The aggregate that is used in the experiment is brought from Suez Area, and its properties meet with the Egyptian specifications. Sand was used to optimize the grading curve of the granular mixture between coarse and fine aggregate. Table (2) shows the grading of fine and coarse aggregate used in all mixes. The water used is tap drinking water meeting with the Egyptian standard specifications. The used superplasticizer has a commercial name of "Sikament NN" which was used to increase the workability of concrete due to the small water to cement ratio.

\subsection{Mix Proportion}

Several mix proportions were tested to study the effective parameters. These mix proportions are shown in Table (3).

\subsection{Mixing procedure of HPC}

Mixing of HPC was batched according to the following procedure: Weigh all constituent materials. Then, Place premix (cement and rice straw ash only) in mixer and mix for 2 minutes (Dry Mix) to break up any clumps. Then, add half of water to premix slowly over the course for 1 minute. After 1 minute, add the remaining water with all Superplasticizer dosage to premix over the course for 3 minutes until HPC changes from a dry powder to a thick paste, where the time (For this process will vary according to the cement content). Then, add sand to the mix for 2 minutes. At the end, add coarse aggregate to the mix for 2 minutes.

\subsection{Curing of HPC}

Concrete specimens were cured in water at room temperature (usually $20^{\circ} \mathrm{C}$ ) before testing.

\subsection{Measurements}

The following properties were measured on fresh concrete by slump, and flow test. Mechanical properties of hardened concrete specimens after 7, and 28 days were measured by.

1. Compressive strength on cube specimens.

2. Flexural strength by one central loading test on prisms specimens.

3. Tensile strength by applying a uniform line load on a cylinder (Brazilian Test).
4. Abrasion resistance on cube specimens.

5. Absorption ratio on cube specimens.

\section{RESULTS}

The results of the different tests are shown in Table (4).

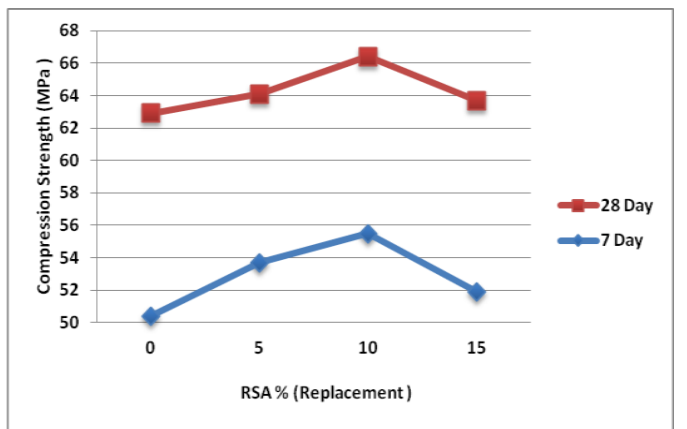

Fig .1: Compressive strength results with different replacement ratios of rice straw ash with cement.

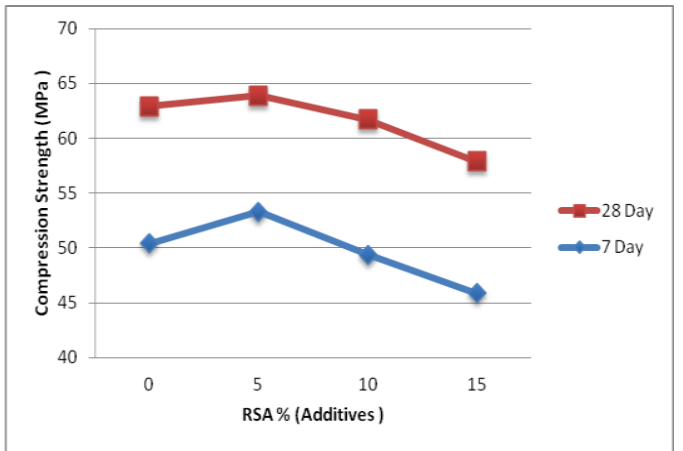

Fig .2: Compressive strength results with different addi tive ratios of rice straw ash with cement.

Based on the results in Table (4), the compressive strength of the cubes of all the mixes with the RSA materials as additives to and replacement of cement by different weight ratio at 7 and 28 days are shown in Table (4) for different mixes respectively. From the results value, a maximum strength of $(66.4 \mathrm{MPa})$ is achieved at age ( 28 days) has been attained by mix (3) that contains $10 \%$ of RSA as replacement of cement contents. On the other hand, the minimum values of cube compressive strength of $(57.9 \mathrm{MPa})$ at age $\{28$ days) were achieved by mixes (7) that contain $15 \%$ of RSA as an additive to cement weight. 
Table (1): The used material.

\begin{tabular}{|c|c|c|}
\hline Material & Type & Characterizes \\
\hline Cement & $\begin{array}{l}\text { Sinai Port land } \\
\text { Cement } \\
52.5 \mathrm{~N}\end{array}$ & $\begin{array}{c}\text { Specific Surface Area }=3590 \\
\mathrm{~cm} 2 / \mathrm{gm} \\
\text { Comply with the Egyptian } \\
\text { standard specifications }\end{array}$ \\
\hline $\begin{array}{c}\text { Fine } \\
\text { Aggregate }\end{array}$ & Sand & $\begin{array}{l}\text { Specific Gravity }=2.6 \mathrm{~g} \mathrm{~m} / \mathrm{cm}^{3} \\
\text { Fineness Modulus }=2.75\end{array}$ \\
\hline $\begin{array}{c}\text { Coarse } \\
\text { Aggregate }\end{array}$ & $\begin{array}{l}\text { Dolomite } \\
\text { limestone }\end{array}$ & $\begin{array}{l}\text { Specific Gravity }=2.6 \mathrm{~g} \mathrm{~m} / \mathrm{cm}^{3} \\
\text { Water Absorption Ratio }=1.85\end{array}$ \\
\hline $\begin{array}{l}\text { Chemical } \\
\text { Admi xture }\end{array}$ & Superplasticizer & $\begin{array}{c}\text { High Range Water Reducing } \\
\text { Admixture } \\
\text { Sikament NN }\end{array}$ \\
\hline Addi ti ve & RSA & Specific Gravity $=2.2 \mathrm{~g} \mathrm{~m} / \mathrm{cm}^{3}$ \\
\hline
\end{tabular}

Table (2): Aggregate Grading

\begin{tabular}{|c|c|c|}
\hline $\begin{array}{c}\text { Sieve } \\
\text { Size }\end{array}$ & Dol omite & Sand \\
\hline 12.5 & 100 & 100 \\
\hline 9.5 & 99.85 & 100 \\
\hline 4.75 & 51.9 & 95.9 \\
\hline 2.36 & 0.3 & 91.22 \\
\hline 1.18 & 0 & 77.63 \\
\hline 0.6 & 0 & 4.05 \\
\hline 0.3 & 0 & 0.91 \\
\hline 0.15 & 0 & 0.02 \\
\hline
\end{tabular}

Table (3): Mix Proportions for the studied mixes

\begin{tabular}{|c|c|c|c|c|c|c|c|}
\hline \multirow[t]{2}{*}{ Index } & \multirow[t]{2}{*}{1} & \multicolumn{3}{|c|}{ Replacement } & \multicolumn{3}{|c|}{ Addi tive } \\
\hline & & 2 & 3 & 4 & 5 & 6 & 7 \\
\hline Cement & 400 & 380 & 360 & 340 & 400 & 400 & 400 \\
\hline$\overline{R S A / C}$ & $0 \%$ & $5 \%$ & $10 \%$ & $15 \%$ & $5 \%$ & $10 \%$ & $15 \%$ \\
\hline RSA & 0 & 12.5 & 25 & 37.5 & 25.3 & 50.6 & 75.3 \\
\hline Water & 140 & 140 & 140 & 140 & 140 & 140 & 140 \\
\hline Dol omite & 1291 & 1291 & 1291 & 1291 & 1291 & 1291 & 1291 \\
\hline Sand & 645.5 & 645.5 & 645.5 & 645.5 & 613.23 & 580.95 & 548.675 \\
\hline $\mathbf{w} / \mathbf{c}$ & 0.35 & 0.35 & 0.35 & 0.35 & 0.35 & 0.35 & 0.35 \\
\hline $\begin{array}{c}\text { Add "Sikament } \\
\text { NN" }\end{array}$ & $1.5 \%$ & $1.5 \%$ & $1.5 \%$ & $1.5 \%$ & $1.5 \%$ & $1.5 \%$ & $1.5 \%$ \\
\hline
\end{tabular}


Table (4): Tests Results.

\begin{tabular}{|c|c|c|c|c|c|c|c|c|c|c|}
\hline \multirow{2}{*}{$\operatorname{Mix}$} & \multirow{2}{*}{$\underset{\%}{\text { RSA }}$} & \multirow{2}{*}{ Curing } & \multirow{2}{*}{$\begin{array}{c}\text { Slump } \\
(\mathbf{C m})\end{array}$} & \multirow{2}{*}{$\begin{array}{l}\text { Slump } \\
\text { Flow } \\
(\mathrm{Cm})\end{array}$} & \multicolumn{2}{|c|}{$\begin{array}{c}\text { Compressive } \\
\text { Strength (Mpa) }\end{array}$} & \multirow{2}{*}{$\begin{array}{c}\text { Flexural } \\
\text { Strength } \\
\text { (Mpa) }\end{array}$} & \multirow{2}{*}{$\begin{array}{c}\begin{array}{c}\text { Tension } \\
\text { Strength } \\
\text { (Mpa) }\end{array} \\
28 \text { Day }\end{array}$} & \multirow{2}{*}{$\begin{array}{l}\text { Abrasion } \\
\text { resistance } \\
\quad(\mathrm{Cm})\end{array}$} & \multirow{2}{*}{$\begin{array}{c}\text { Absor ption } \\
\%\end{array}$} \\
\hline & & & & & 7 Day & 28 Day & & & & \\
\hline 1 & 0 & Standard & 20.5 & 45.5 & 50.4 & 62.9 & 11.4 & 7.1 & 1.4 & 1.58 \\
\hline 2 & 5 & Standard & 19.5 & 44.9 & 53.7 & 64.1 & 11.6 & 6.9 & 1.55 & 1.75 \\
\hline 3 & 10 & Standard & 15.5 & 40.2 & 55.5 & 66.4 & 12.1 & 6.7 & 1.75 & 1.81 \\
\hline 4 & 15 & Standard & 10.3 & 35.8 & 51.9 & 63.7 & 11.5 & 6.2 & 2.1 & 1.92 \\
\hline 5 & 5 & Standard & 19.8 & 45.1 & 53.3 & 63.9 & 11.2 & 6.5 & 1.35 & 1.44 \\
\hline 6 & 10 & Standard & 17.2 & 41.2 & 49.4 & 61.7 & 10.9 & 6.1 & 1.45 & 1.6 \\
\hline 7 & 15 & Standard & 13.9 & 36.7 & 45.9 & 57.9 & 9.8 & 5.9 & 1.9 & 1.77 \\
\hline
\end{tabular}

\subsection{Statistical Analysis and Discussion}

The main focus of this research is to produce a high performance concrete and to determine the impact of adding rice straw ash with different proportions on different properties of HPC. The effect of the proportions of the ingredients of concrete on the development of mechanical properties of concrete are shown in Figures (1), and (2).

Based on the results in Table (4), in case of replacement, the optimum content of RSA is $10 \%$. Strength value in this case is (66.4) MPa. In case of an additive, the optimum content of RSA is $5 \%$. Strength value in this case is (63.9) MPa.

\subsubsection{Compre ssive strength.}

The results shown in Table (4) indicate that the compressive strength of RSA concrete mixes increases as the RSA content has increased at all the ages in case of replacement in comparison with the control mix. Figure (3) shown above represents the development of compressive strength due to the increase in RSA content in concrete form $0 \%$ to $1.055 \%$ in mix (3) at (28 Day). Table (4) contains the total results for compressive strength results with additive or replacement different ratios of rice straw ash with cement. From those values, the maximum strength of (66.4MPa) that is achieved at age ( 28 days) has been attained by mix (3) that contains $10 \%$ of RSA as replacement of cement content. On the other hand, the minimum values of cube compressive strength of (57.9MPa) at 28 days could be achieved by mixes (7) that contains $15 \%$ of RSA as an additive to cement weight.

\subsubsection{Concrete age for HPC with RSA.}

With regard to the effect of age on compressive strength, figures (1) and (2) indicate that there is a

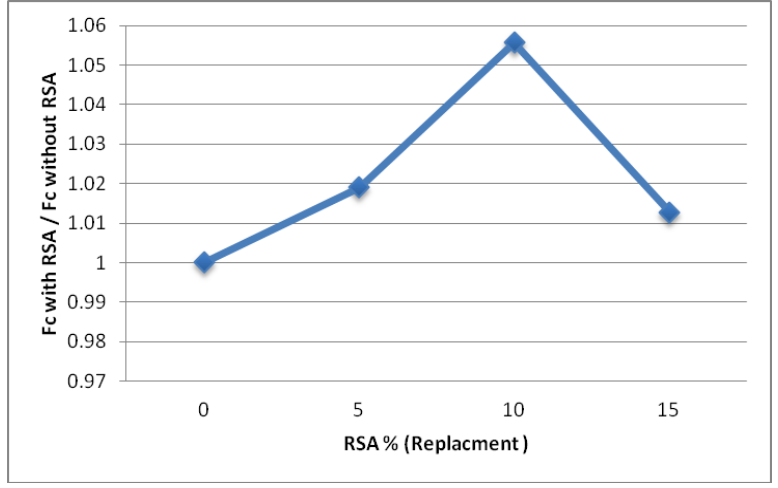

Fig.3: Effect of rice straw ash on compressive strength for Mix containing different ratios from rice straw ash replacement with cement at (28 Days)

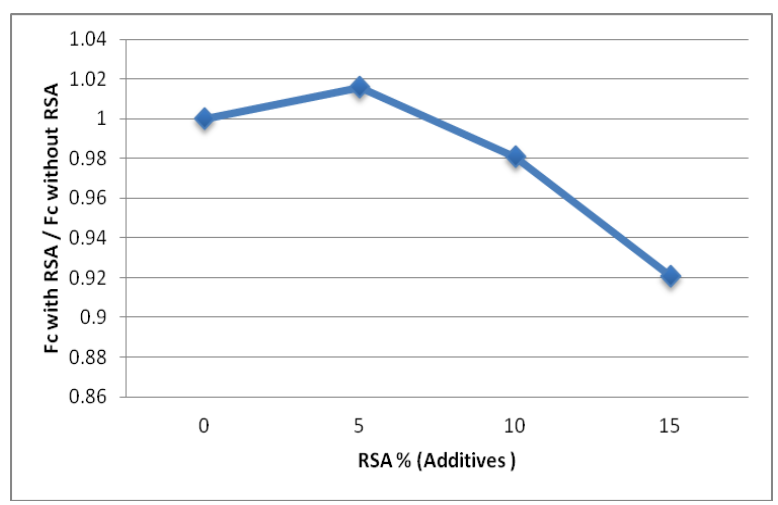

Fig.4: Effect of rice straw ash on compressive strength for Mix contains different ratios from rice straw ash additives with cement at (28 Days).

direct proportional relationship between the age and strength at 28 days. This means that the hydration process is still active at this concrete age and there is no negative effect of RSA materials in the long-term 
hydration rates. These results may be considered to be the main advantage of utilizing RSA in concrete mixes. However, 28 day compressive strength was higher than that of 7 days for all mixes by about $(10 \sim 20 \%)$ as seen from results shown in Table (4).

\subsection{Early Strength Gain for HPC.}

The compressive strength gain behaviour of HPC is an important characteristic of the concrete. Results in this research are shown in Table (4), the compressive strength gain after 7 days about $(0.75-0.85 \%)$ from compression strength at 28 day. From values the maximum strength of (55.5MPa) which was achieved at age (7 days) has been attained by mix (3) that contains $10 \%$ of RSA as replacement of cement contain. On the other hand, the minimum values of cube compressive strength $(45.9 \mathrm{MPa})$ at 7 days could be achieved by mix (7) that contains $15 \%$ of RSA as additive to cement weight. From the results RSA, an increase in the compressive strength due to pozzolanic effects up to $10 \%$ rep lacement with cement contains.

\subsection{Analysis of the Relations between the Mechanical Properties and Compressive Strength for HPC:}

\subsubsection{The relation between compression and flexural strength}

The relation between rice straw ash percentage and the ratio between flexural to compressive strength $(\mathrm{Fb} / \mathrm{Fc})$ for the studied mixes shown in figures (5) and (6). The results show that the relation between compressive and flexural strength for HPC, in case of $0 \%, 5 \%, 10 \%$, and $15 \%$ rice straw ash as different ratios of cement content by weight as additives and replacement. Figures (5) and (6) show the relation between compressive and flexural strength for mixes 1 , $2,3,4,5,6$ and 7 respectively.

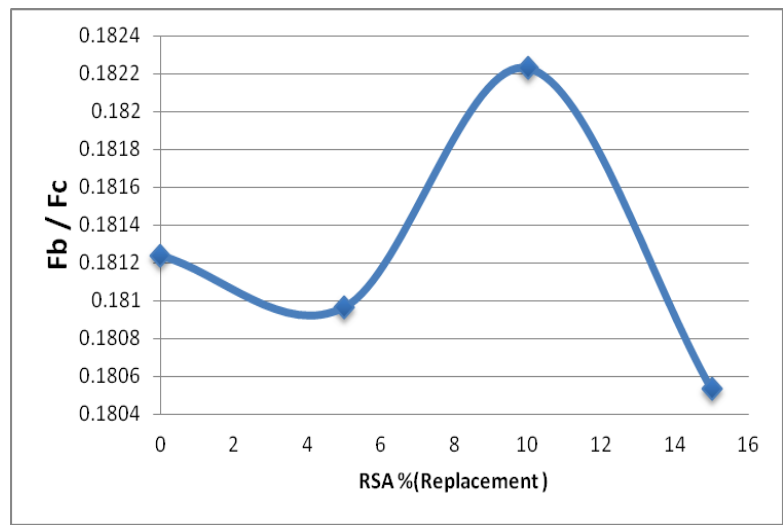

Fig.5: Relation between flexural and compression strength for mixes $(1,2,3,4)$.

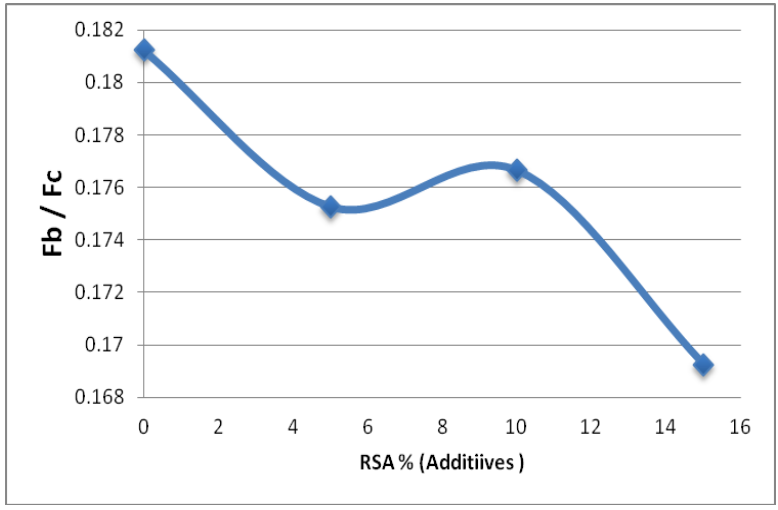

Fig.6: Relation between flexural and compression strength for mixes $(1,5,6,7)$.

\subsubsection{The relation between the compression and tensile strength}

The relation between rice straw ash percentage and the ratio between tensile to compressive strength $(\mathrm{Ft} / \mathrm{Fc})$ for the studied mixes shown in figures (7) and (8). The results show that the relation between compressive and tensile strength for HPC, in case of $0 \%, 5 \%, 10 \%$, and $15 \%$ rice straw ash as different ratios of cement content by weight as additives and replacement. Figures (7) and (8) show the relation between compressive and tensile strength for mixes 1, $2,3,4,5,6$ and 7 respectively.

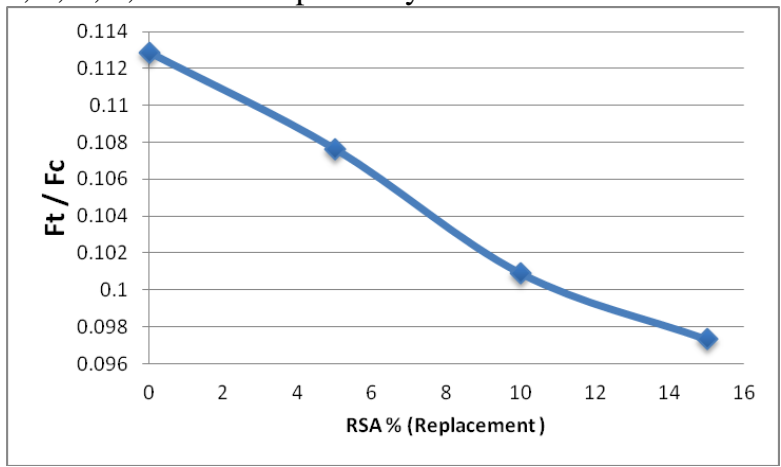

Fig.7: Relation between tensile and compression strength for mixes $(1,2,3,4)$.

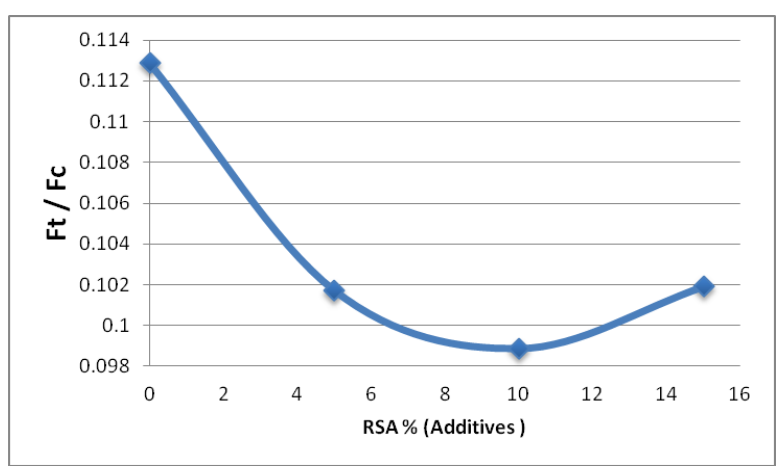

Fig.8: Relation between tensile and compression strength for mixes $(1,5,6,7)$. 


\subsubsection{Relation between compression strength and abrasion resistance:}

Figures (9) and (10) show the relation between compressive strength and abrasion resistance for the studied mixes. The results show that the relation between compressive and abrasion resistance for HPC, in case of $0 \%, 5 \%, 10 \%$, and $15 \%$ rice straw ash at different ratios of cement content by weight as additives and replacement . Figures (9), and (10) show the relation between compressive and abrasion resistance for mixes $1,2,3,4,5,6$, and 7 respectively.

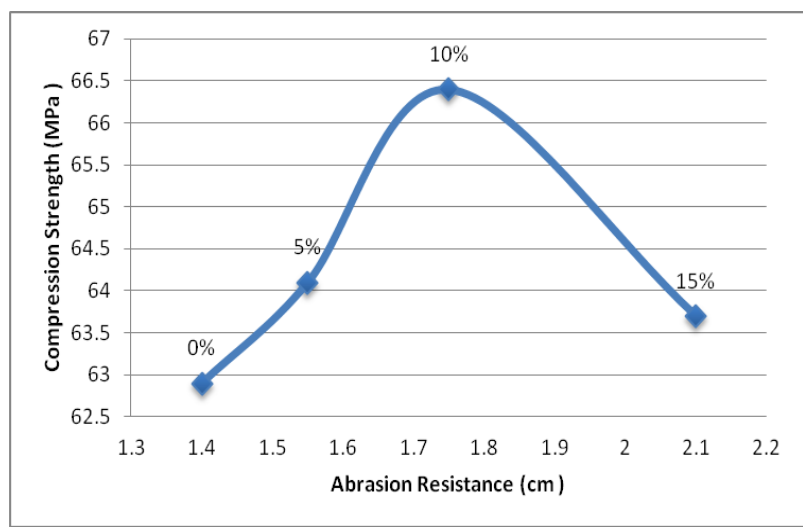

Fig.9): Relation between compression strength and abrasion resistance for Mix contains different ratios of rice straw ash replacement with cement in (28 Days).

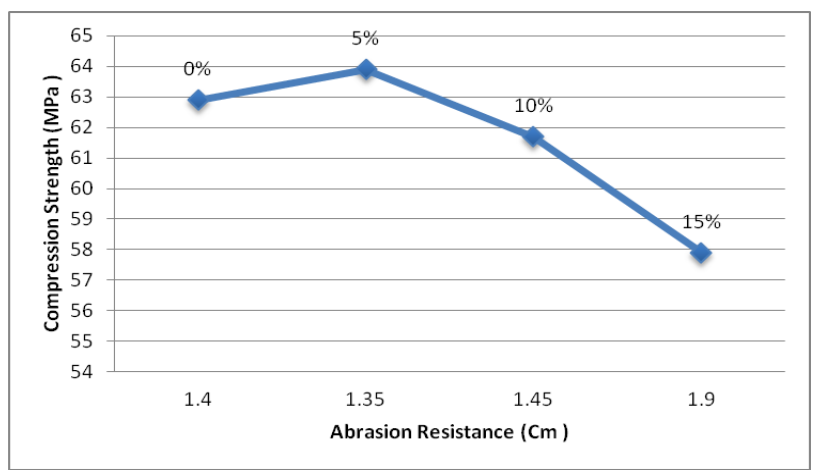

Fig. 10: Relation between compression strength and abrasion resistance for Mix contains different ratios of rice straw ash additive with cement in (28 Days).

\subsubsection{The relation between the compression and absorption ratio:}

Figures (11) and (12) show the relation between compressive strength and absorption ratio for the studied mixes. The results show that the relation between compressive and absorption ratio for HPC, in case of $0 \%, 5 \%, 10 \%$, and $15 \%$ rice straw ash at different ratios of cement content by weight as additives and replacement. Figures (11), and (12) show the relation between compressive and absorption ratio for mixes $1,2,3,4,5,6$, and 7 respectively.

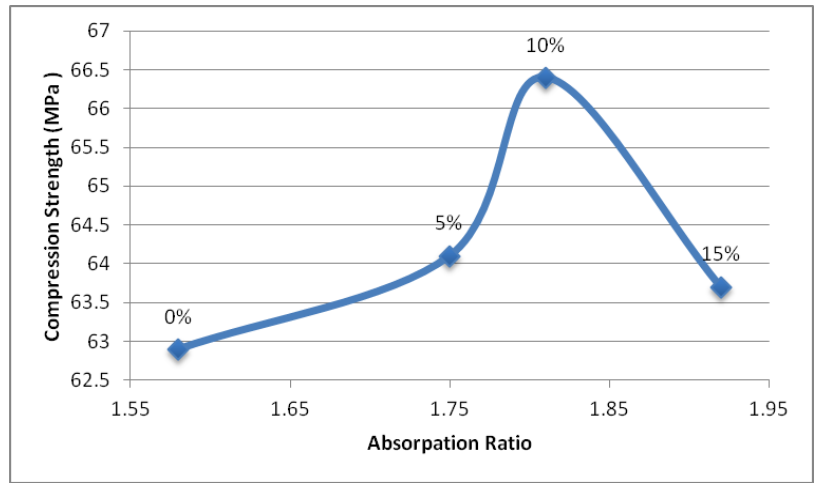

Fig.11: Relation between compression strength and absor ption ratio for Mix contains different $r$ atios of rice straw ash replacement with cement in $(28$ Days).

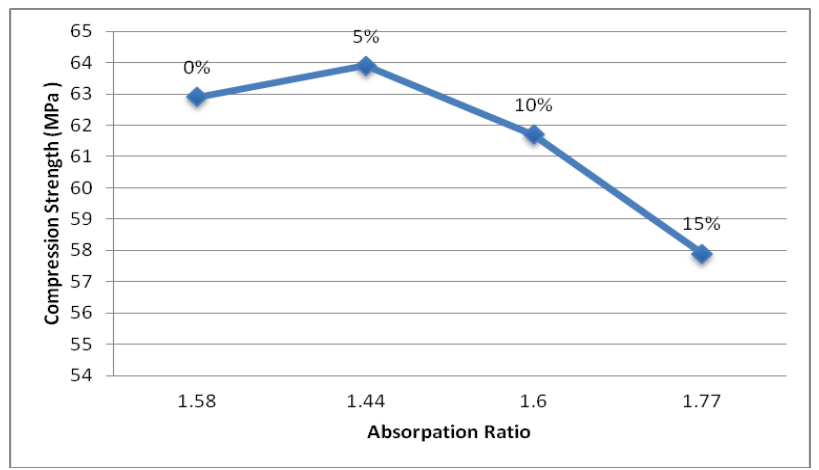

Fig.12: Relation between compression strength and absor ption ratio for Mix contains different ratios of rice straw ash additive wi th cement in (28 Days).

\section{CONCLUSIONS}

The following conclusions are based on the experimental work presented in this paper.

1. RSA is a highly reactive pozzolanic material and can be used as a supplementary cementing material to produce High Performance concrete.

2. The slump consistency of the concrete was reduced due to the use of the RSA as cement replacement or additive. Thus, it was necessary to increase the amount of superplasticizer in the mixtures containing RSA to obtain the same consistency of the reference mix.

3. The concrete with rice straw ash at $10 \%$ replacement has a greater compressive strength value at 28 days as compared with control mix.

4. Based on the results of tensile strength, it is to state that there is no increase in tensile strength due to addition of RSA. 
5. The flexural strength studies indicate that there is a marginal improvement with $10 \%$ RSA replacement.

6. 6. was reduced due to the use of the RSA as cement rep lace ment or additive.

7. Based on the results, all mixes with RSA as replacement or additives with cement contain increase the absorption ratio.

\section{REFERENCES}

[1] Mansour et. al, "Development of Straw-cement Composite Sustainable Building Material for Low cost Housing in Egypt" Journal of Applied Sciences Research, 3(11):1571-1580, 2007.

[2] Terra Daily, 2003. "Burning rice chaff blamed for autumn pollution in Cairo "http://www.terradidly.com/2003/031019124213. m4948my 4.html, October 2003.
[3] AFP, 2003. "Burning rice chaff blamed for autumn pollution in Cairo ", Agence France Presse (AFP), Cairo, October , 19-2003.

[4] Yousry el-shikh m. Mohamed, "Burned Rice Husk Ash as Additives and Replacement of Cement in Mortar", Mansoura University, EGYPT, 2008.

[5] Kazragis, A.2005. Minimization of atmosphere pollution by utilizing cellulose waste. Environmental Engineering and Landscape Management, 13(2): 81-90.

[6] Yousry el-shikh m. Mohamed, "burned rice straw in concrete" the 6 th. Engineering International Conference 2008, 18-23 March, Mansoura Sharm Al shikh, EGYPT.

[7] Design and Control of Concrete Mixtures,EB001, 14th edition, Portland Cement Association, Skokie, Illinois, USA, 2003.

[8] "Compressive Strength Of Concrete Blended With Calcined Rice Straw Ash ",The 3rd ACF International Conference - ACF/VCA -2008. 